\title{
The Exploration of the Management Mode of Students'Education in School-Enterprise Cooperation
}

\author{
Gan Juan, Chunxi Wang \\ $X i$ 'an Aeronautical University, Xi'an, Shaanxi, 710077
}

\begin{abstract}
The mode of cooperation between school and enterprise in higher vocational colleges has been widely used and recognized enough. In the process of cooperation between schools and enterprises, the teaching work of higher vocational colleges will face more challenges and needs. Therefore, it is necessary to study the management mode according to the training plan and the growth characteristics of students in higher vocational colleges. Then all kinds of problems can be solved effectively. This paper discusses the educational management mode of school-enterprise cooperation students in colleges and universities.
\end{abstract}

Keywords: cooperation between school and enterprise; education management; exploration

Compared with undergraduate student management, there are great differences in student management in higher vocational colleges, especially in China, many higher vocational colleges are upgraded from secondary vocational colleges, so there are many problems in practical management. With the continuous progress of school-enterprise cooperation, higher requirements are put forward for student management in higher vocational colleges. How to meet the challenge and complete the innovation better is a problem worth thinking about for the management of higher vocational education, so as to cultivate high-quality technical talents to meet the needs of enterprises.

https://doi.org/10.47852/bonviewCETR2020010222

This is an open access article published by the BON VIEW PUBLISHING PTE. under the Creative Commons Attributions License. 


\section{Requirements for Student Management in Cooperation between Schools and Enterprises}

The training plan of higher vocational colleges clarifies the teaching management mode of combining higher vocational education with enterprises, and combines the actual needs of enterprises to train talents in various industries. Therefore, there are many forms of school-enterprise cooperation training mode, in order to create school-enterprise cooperation training departments and factories to achieve the school, students, enterprises win-win. Under this background, we must fully think about how to better manage students, help students to more clearly meet the needs of society, understand corporate culture, strengthen their own practical work ability. Student management is a strong guarantee of cooperation between school and enterprise, and the school must carry out innovative work in concept and working mode ${ }^{[1]}$.

First, in the process of cooperation between schools and enterprises, the main body of education is more diversified, and teachers are regarded as the main body of education in the past school education. In the mode of cooperation between school and enterprise, teachers and masters are taken on the main body of education together, and the transformation of the main body of education brings great changes to the guidance and examination of education. Must clearly divide the responsibility, needs the teacher and the master to communicate with each other better. Teachers need to know more about the production management of enterprises, and teachers need to know more about education training and management. In this way, we can ensure the effective management of students, so that the teaching work can be carried out smoothly. Second, under the background of school-enterprise cooperation, the identity of the educatee has also changed. In the past, the educatee in education was mainly students, but under the promotion of the mode of school-enterprise cooperation, in addition to higher vocational students, It also includes apprentices and employees. Some students have a certain sense of superiority to their identity, too idealized, this inaccurate positioning leads to a large psychological gap, thus losing self-confidence, in the role of the change lost direction. This requires proper guidance for students' psychology in student management, guiding students to position correctly, facing the reality calmly, and making reasonable plans for the future. Third, under the background of school-enterprise cooperation, the educational environment has changed greatly. From campus to enterprise, there are many problems in the transformation of environment, such as the complication of interpersonal relationship, the students can not adapt, the management mode of the enterprise and the heavy work task all make the students resist the emotion. Students from a harmonious environment to the interests of the premise and focus on hard work environment, there will be a variety of unsuitable. So the relevant managers 
must mediate the existing problems so that students can adapt to the social environment more quickly. Fourth, under the background of school-enterprise cooperation, the teaching goal is to cultivate students' practical ability, and production practice is an important content of examination, so it has higher requirements for students' professional skills and practical ability. In contrast, the theoretical basis is not too high, which requires teachers to make specific adjustments to student management.

\section{Adhere to the "people-oriented" concept of student management}

First, we must set up a "student-oriented" teaching concept. In the process of practical teaching management, students must be encouraged to realize their own value, so the management is very effective. According to the basic concept of student education, the Ministry of Education makes students become the main body of student management, and links it into the whole student management link, respects students and cares about the future development of students. Second, set up the teaching idea of moral education first. The main goal of school-enterprise cooperation is to cultivate high-quality talents with strong comprehensive ability. This kind of education not only exists on campus, but also needs to take moral education as the starting point to carry out ideological and political education for students. For example, it can combine corporate culture, employment requirements and family education into different activities on campus, and at the same time, it can also enable students to carry out moral education to students in the form of backhand campus atmosphere in enterprises ${ }^{[2]}$.

\section{Institutional innovation to standardize student management}

The main purpose of innovation management system is to achieve the best effect through institutionalized innovation mode. For example, the establishment of practice application system, regular inspection system ," three tutors "system, pre-job training system, registration and filing system, evaluation incentive system and so on. Through the internship application system, students can choose their own internship, thus avoiding the resistance caused by the arranged students. The pre-job training system refers to the training of students' production safety and discipline in order to adapt to the work position as soon as possible before the practice, so as to enhance the students' ability to protect themselves. The "three tutors" system is to manage the students by three tutors, record the main contents of student management and evaluate them in time. Regular inspection system is that school administrators often understand the specific situation of students through enterprises and interns, and give effective advice. Evaluation incentive system refers to the school combined with teaching objectives and credits, according to the performance of students in the enterprise, the establishment of 
performance assessment and reward and punishment system. Registration and filing system means that the specific information of interns needs to be put on record in the student management system and office, and can be checked at any time.

\section{Enhancing students' professional quality}

Vocational quality training is the main measure of school-enterprise cooperation mode in higher vocational colleges. First of all, it is necessary to carry out more targeted quality education for students in the form of education and management. At the same time, in order to improve the employment rate and better adapt to work, a variety of activities are needed to enhance students' interpersonal skills. Secondly, according to higher vocational colleges and enterprises, we should pay more attention to cultivating students' ability in all aspects and create a harmonious working environment for cooperative education. Let enterprises play the role of practical education to the greatest extent, attach importance to students' practical education, and strengthen students' recognition of their own profession. In practice, constantly develop excellent professional literacy, for the future into the job to lay a solid foundation ${ }^{[3]}$.

\section{Improving management methods and improving management}

If the school does a good job of ideological education before the students practice, the students will be more active in the enterprise, and can follow the management and will not violate the discipline, actively learn new skills. However, after a period of time, some students gradually lost their freshness, or because they could not adapt to the working environment and encountered difficulties. In this process, schools need to improve management methods. First, enterprise management. By means of the management concept of enterprise $6 \mathrm{~S}$, the school must standardize the students' behavior, in order to adapt to the enterprise management as soon as possible and enhance the intern's self-management consciousness. Second, process management. Mainly reflected in the process planning testing, implementation, improvement. Student management is to pay attention to the ideological and political education of interns, learn to be human and do things, and play the role of process education. Third, the implementation of information management. Guide students to use WeChat, QQ group and other means to communicate effectively, so that schools and enterprises can get effective information feedback and can cooperate with management. Fourth, flexible management. In the process of practice, because the students have not graduated, at the same time, they are not regular employees, so the effective implementation of two-way assessment, the way of assessment is relatively flexible. Fifth, emergency management. According to the situation of students in practice, the relevant education departments and 
schools need to set up emergency plans to strengthen the ability to deal with emergencies ${ }^{[4]}$.

\section{In the face of the real working environment, cultivate students' will to bear hardships and stand hard work}

Consciousness can effectively play the role of action, but also in the face of difficulties have a super ability. If students can have a better will, they can work harder to achieve the best learning results. Most of the students trained by higher vocational colleges will become technical workers in production line positions. Without the spirit of hard work, students can not take up future jobs. Students come to enterprises from a campus with superior environment. In the face of jobs and work contents, their working environment is also more complex, coupled with the diversity of interpersonal relationships. It is inevitable to encounter a variety of difficulties. How to deal with many difficulties is a test of willpower for students.First, teaching teachers need to make students realize that practice is the stage of turning knowledge into technical ability, and it is also an important period to learn from workers. In this stage, students need to improve their understanding of the work, so that they can find their own position. It also strengthens the team spirit of the students, and makes the students clear the importance of starting from the post and starting from the grass roots, so as to cultivate their own excellent quality. Second, teachers encourage interns to actively participate in the work, according to the difficulties encountered in the work process to give timely adjustment, and then make it adapt to the working environment as soon as possible. Third, guidance teachers can design some difficulties for students in their work, so as to better temper students' will.

\section{Clarify the significance of cooperation between schools and enterprises and mobilize students' learning motivation}

As a result of joining the school-enterprise cooperation program, some students may not understand, there is no school attention. Therefore, before students enter the internship position, teachers need to let students understand the significance of this learning method, and then according to the characteristics of their jobs to carry out a systematic pre-internship training work. Enhance students' understanding of enterprises and jobs, and have the motivation to actively participate in cooperative projects. If it is not for the graduating class to join the the teacher needs to encourage the students to look at the problem more rationally, to see their own advantages, and to face it with a positive attitude. If the graduating students join the cooperative project, they can be more familiar with the working environment through the internship, so as to cultivate the students' practical ability and accumulate work experience ${ }^{[6]}$. 


\section{Conclusion}

With the development of society, the mode of cooperation between school and enterprise is the inevitable direction of the development of higher vocational colleges in the future. With the continuous reform of the education system, the innovation of student management has become more complex. Therefore, in the development process of higher vocational colleges, we must pay more attention to the management of students, and understand the problems and challenges faced by the current work. Through the system and work form as the starting point, gradually improve the working ability, and then improve the comprehensive strength of students, to contribute to the socialist development of our country.

\section{References}

[1] Ju Feng. Discussion on Countermeasures of Student Management in Higher Vocational Colleges under the New Mode of School-Enterprise Cooperation J]. Internet Environment Technology Information ,2019,17(12):164 166.

[2] Ma Jun, Liu Tong, Xia Yunchao. Exploration on the New Mode of Cultivation of Cooperative Talents in Local Colleges and Universities under the Background of Mass entrepreneurship and innovation and J]. Engineering Curriculum Education Research: study of Learning methods and Teaching methods 2018(11):42-43.

[3] Dong Yongyan. A Practical Exploration on Ideological and Political Education in Higher Vocational Colleges under the Mode of Cooperation J]. Schools and Enterprises Scientific Advisory (Science and Technology Management),2018,(32):140-141.

[4] Fang Fang. Exploration on the Teaching Path of Economic Management Specialty in SchoolEnterprise Cooperation Model [J].].1 Business ,2018,(34):256-256.

[5] Zhang Xiao, Di Kui, Chen Chen, et al. Exploration and Practice of Practical Training Teaching Management in School-Enterprise Cooperation Mode [J].] Experimental Technology and Management, v.35;No.262(6):191-195,2018 198.

[6] Zhang Jingsha. A Study and Practice on the School-Enterprise Cooperation Model of Information Specialty in Applied Colleges and Universities [J].]1 Modernization of education ,2020,7(10):20-22.a 